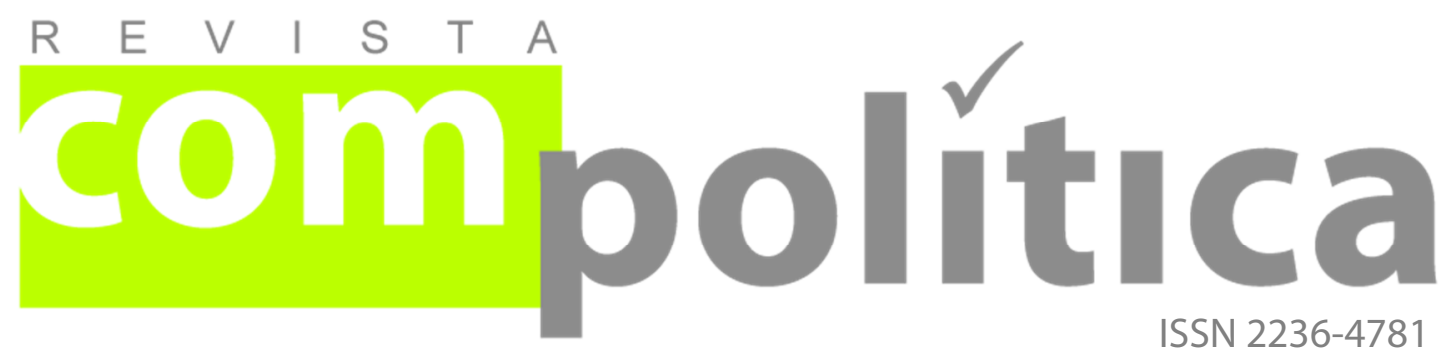

OLIVEIRA, Vanessa Veiga de

Doutoranda do Programa de Pós-Graduação em Comunicação Social da UFMG.

<veiga.jornalismo@gmail.com>

\title{
Desafios para o avanço dos direitos humanos no Brasil: uma análise das justificações no debate mediado em torno do caso do PNDH-3
}

\section{RESUMO}

Com o objetivo de refletir sobre os desafios para a promocão dos direitos humanos no contexto brasileiro, este artigo apresenta as características do debate que ocorreu nos media acerca do PNDH-3 (Terceiro Programa Nacional de Direitos Humanos) e os efeitos dessa visibilidade para a formação da decisão política. O caso em tela é controverso, pois após o programa ser objeto de intenso debate e de pressão política, seu texto foi novamente publicado em maio de 2010, com a alteração de importantes pontos que contrariavam a proposta original. A partir do método DQI (Discourse Quality Index), o artigo analisa a cobertura midiática e as razóes ensejadas pelos atores durante a contenda. Revela-se que 0 cenário desigual de acesso à visibilidade midiática privilegia as justificações dadas por grupos de interesse específico, sobrepondo-se ao bem comum, desconsiderando o objetivo primeiro da política em questão, os direitos universais.

Palavras-chaves: Deliberação, Debate mediado, Direitos Humanos.

\section{ABSTRACT}

We aim to reflect on contemporary challenges to the promotion of human rights in the Brazilian context, hence this work presents the characteristics of the mediated debate about the PNDH-3 (Third National Program for Human Rights) and the effects of media visibility to decision-making. The case in point is controversial, because the program was the subject of intense debate in the media scene and of political pressure, which led to change its several points, again published in May 2010, an election year. The paper seeks to analyze the media coverage and the reasons given by actors during the contest. We use the DQI method (Discourse Quality Index), and identified an unequal access scenario where media visibility interest groups overlap the common good, disregarding the primary objective of the policy concerned: the universal rights

Key words: Deliberation, Mediated Debate, Human Rights. 


\section{Desafios para o avanço dos direitos humanos no Brasil: uma análise das justificações no debate mediado em torno do caso do PNDH-3}

\section{[Challenges for human rights policies in Brazil: an analysis of justifications in mediated debate involving PNDH-3]}

OLIVEIRA, Vanessa Veiga de

o longo da história do Brasil, percebemos uma constante
tentativa de construir a efetivação dos direitos humanos no país e a ampliação do acesso desses direitos à população. A proposta do Programa Nacional de Direitos Humanos (PNDH), o programa que reúne as diretrizes para as políticas públicas de promoção dos direitos humanos no país, surge no intuito de aproximar o "Brasil legal" - que se refere à avançada legislação brasileira, a qual assegura as garantias universais por meio da Constituição, de leis, de estatutos e outras ferramentas jurídicas - do "Brasil real", ou seja, das mazelas sociais, econômicas, culturais e políticas que violam sistematicamente a dignidade humana de milhares de brasileiros. 0 programa, já editado em três versões, desde 1996, configura-se como uma tentativa de articular o Estado com a sociedade civil no estabelecimento de ações estratégicas para garantir os avanços dos direitos humanos no país. Muitas das medidas previstas nas três versões $^{1}$ já produzidas visavam transformações estruturais na

\footnotetext{
${ }^{1}$ O contexto de criação do primeiro PNDH, ainda em 1996, está ligado às duras cobranças de organismos internacionais por uma política pública de direitos humanos após a redemocratização do Brasil. Em 1988, quando a Constituição Federal foi promulgada, o país estava imerso em problemas sociais ligados à desigualdade econômica, à persistência de racismo e machismo, à urgência da reforma agrária, à visão preconceituosa em relação aos índios, ao medo de tocar no passado recente e desvelar os horrores dos porões da ditadura e aos índices
} 
sociedade por meio de reformas e de decisões tomadas nos planos nacional e internacional (BARAZAL, 2005). Pode-se dizer, então, que os PNDH's representam uma política ambiciosa ao pretender harmonizar o discurso sobre democracia efetiva.

Para alcançar tais objetivos, o PNDH é construído na tentativa de reunir esforços conjuntos envolvendo o governo brasileiro, a sociedade civil organizada (como ONG's e movimentos sociais), e a população em geral. O propósito sempre é o de traduzir direitos garantidos pelo Estado por meio de metas (de curto e médio prazo), com objetivos claros e com múltiplos alcances (ADORNO, 2010, p.7).

Este artigo explora o processo de justificação, da construção discursiva e de definições acerca da mais recente versão do PNDH e, certamente, a mais polêmica ${ }^{2}$ : o Terceiro Programa Nacional de Direitos Humanos (PNDH-3). O programa é constituído por uma agenda de 521 ações programáticas, distribuídas em 25 diretrizes, 82 objetivos estratégicos e seis eixos.

O PNDH-3 representa um verdadeiro roteiro para seguirmos consolidando os alicerces desse edifício democrático: diálogo permanente entre Estado e sociedade civil; transparência em todas as esferas de governo; primazia dos Direitos Humanos nas políticas internas e nas relações internacionais; caráter laico do Estado; fortalecimento do pacto federativo; universalidade, indivisibilidade e interdependência dos direitos civis, políticos, econômicos, sociais, culturais e ambientais; opção clara pelo desenvolvimento sustentável; respeito à diversidade; combate às

alarmantes de desemprego e criminalidade. Com essa demanda, o Primeiro PNDH foi lançado em 1996 e foi construído em colaboração com o Núcleo de Estudos da Violência da USP, coordenado pelo professor Paulo Sérgio Pinheiro. Uma nova versão do documento foi apresentada em 2002, ambas as versões durante o governo do presidente Fernando Henrique Cardoso. O segundo PNDH foi celebrado pela sociedade civil brasileira como um documento completo, diverso, que respondia às demandas da realidade do país. O PNDH-3 surgiu, então, em 2009, já no governo do presidente Luís Inácio Lula da Silva, como uma continuidade à segunda versão ${ }^{1}$, sendo sua mais destacada característica o detalhamento dos caminhos para executar cada questão abordada, a maioria delas já pensadas e brevemente apresentadas no PNDH-2.

${ }^{2}$ Sobre isso, ver: Adorno (2010), Oliveira (2013), Barazal (2005), Gregori (2008), Dallari (1998), Lima Junior (2002). 
desigualdades; erradicação da fome e da extrema pobreza. (BRASIL, 2010, p.11).

A proposta de interpretar o sentido dos direitos humanos a partir do caso do PNDH-3 foi motivada devido à repercussão do debate que se instaurou em torno do programa a partir de sua publicação, em dezembro de 2009. Foi possível identificar uma acirrada troca de razões relacionadas a algumas questões específicas do decreto, as quais demandavam a alteração, e até a revogação, do mesmo. A polêmica ganhou ampla repercussão, provocando uma crise de governo, ameaças de demissão e arriscando as alianças no cenário eleitoral de 2010. A expectativa era de que o programa, por sua abrangência e elaboração, representaria a conciliação dos diversos interesses e necessidades que envolvem os direitos humanos no país. No entanto, encontramos nas falas que tentavam justificar os problemas do PNDH-3 novamente aquilo que era a motivação de nossas reflexões iniciais: o quão controverso é o significado dos direitos universais na sociedade brasileira.

Este trabalho busca analisar, especificamente, as justificativas dadas no debate em torno do PNDH-3 na mídia. Após explicarmos nossas escolhas metodológicas, pautadas especificamente pelo método DQI (Discourse Quality Index) desenvolvido por Steiner et al. (2004, 2012), apresentamos os resultados empíricos dessa análise que são, então, correlacionados às decisões políticas tomadas pelo governo em diferentes momentos deliberativos envolvendo a política pública em tela. O objetivo final é refletir sobre como os achados da análise empírica estão relacionados com os significados dos direitos humanos no país, uma vez que as controvérsias do programa espelham o conflito existente atualmente entre um Brasil legal e um Brasil real. 


\section{O processo de justificação: contribuições da teoria da democracia deliberativa}

Durante todo o processo de discussão do PNDH-3 (desde sua criação durante as conferências públicas, seu debate nos media e sua reformulação em maio de 2010) há a existência de um processo político que envolve argumentação. Diferentes atores com interesses nas políticas que estavam sendo definidas a partir do programa ensejaram-se na contenda. Do mesmo modo, o governo era compelido a dar respostas e soluções às demandas que surgiam. Nesse sentido, pretendemos explorar neste artigo a questão de como determinados temas do PNDH-3 foram justificados (seja a favor ou contra) em seus diferentes momentos. Compartilhamos, portanto, da teoria da democracia deliberativa (BOHMAN, 1996; CHAMBERS, 2003: COHEN, 1997: DRYZEK, 2000: GUTMANN, THOMPSON, 1996, 2004; HABERMAS, 1997: MAIA, 2008, 2012: PARKINSON, 2006) a fim de problematizar os debates instaurados a partir de controvérsias específicas envolvendo o programa.

A justificação está no cerne do conceito da deliberação, tanto que ela pode ser entendida como uma "troca pública de razões" (COHEN, 1997, p.73). A deliberação constitui-se como um processo inteligível de discussão, no qual os atores podem expressar seus pontos de vista e refletir acerca das ponderações levantadas pelos outros atores. Desse modo, constrói-se um ambiente argumentativo em que os indivíduos são compelidos a debater uma questão que interessa a todos. Assim, "a deliberação é racional na medida em que os participantes são chamados a enunciar seus argumentos a favor das propostas feitas, a suportá-los ou criticá-los" (COHEN, 1989, p.22.). Os participantes devem sustentar suas proposições apenas de maneira argumentativa, sendo que o debate deve ser livre de coerções internas e externas, e as tomadas de posição devem ser motivadas “pela força não coativa do melhor argumento” (HABERMAS, 1997). 
De tal modo, a justificação ocupa um lugar chave dentro da teoria deliberacionista e é também o objeto de reflexão deste trabalho. A importância da argumentação no processo de tomada de decisão é ressaltada por Dryzek (2004), que diz: “pretensões a favor ou contrárias a decisões coletivas requerem justificação àqueles submetidos a essas decisões nos termos que, mediante reflexão, esses indivíduos podem aceitar" (DRYZEK apud MAIA, 2008, p.28). Assim, a democracia deliberativa exige que aqueles que tomam a decisão devem ficar comprometidos a justificarem suas escolhas e de serem sempre accountable (GUTTMAN; THOMPSON, 2004, p.78).

Nesse tipo de democracia, percebemos que a existência do desacordo, quando este leva a um debate ancorado na racionalidade, é necessária para aprimorar a vida em sociedade, bem como para eliminar a tirania da vida política. Habermas (1997) destaca que esse processo de justificação valoriza a força do melhor argumento dentro de uma diversidade de discursos que se interceptam e se sobrepõem (MAIA, 2008). Como diz Guttman e Thompson:

Podemos definir a democracia deliberativa como uma forma de governo na qual cidadãos livres e iguais (e seus representantes) justificam suas decisões em um processo no qual apresentam uns aos outros motivos que são mutuamente aceitos e geralmente acessíveis, com o objetivo de atingir conclusões que vinculem no presente todos os cidadãos, mas que possibilitam uma discussão futura. (GUTTMAN; THOMPSON, 2004, p.23).

De tal maneira, o processo de justificação requer duas posturas básicas dos sujeitos que participam dos debates. Primeiro, é preciso que eles não apenas exponham suas posições, mas justifiquem-nas; e, em segundo lugar, que eles reconheçam a existência de uma pluralidade de visões na sociedade e estejam dispostos a serem interlocutores com os demais (GOMES; MAIA, 2008). Como afirma 
James Bohman (1996, p.421) ${ }^{3}$, "processos de justificação exigem um esforço dos cidadãos para que eles possam ir além dos interesses próprios, típico das associações, e se orientem pelo bem comum". De tal modo, podemos dizer nos termos de Guttman e Thompson (2004) que o objetivo da deliberação é diminuir a discordância moral entre os sujeitos por meio da justificação. Isso significa que a deliberação "pode ajudar seus participantes a reconhecer o mérito moral presente nas exigências de seus oponentes, quando estas possuírem méritos" (GUTTMAN; THOMPSON, 2004, p.27).

Por meio da troca argumentativa, a deliberação visa afastar-se de práticas como a barganha e a chantagem. Contudo, na prática política há muitos momentos em que essas formas de tomada de decisão são acionadas (CHAMBERS, 2005, 2009). 0 jogo político inclui diversas formas de interação entre as forças políticas, tais como acordo, articulação, acerto, barganha (novamente), alianças, retaliações, composições, compensações, de maneira que a vida política constitui-se como uma constante negociação política (GOMES, 2004, p.83), dado que "nem todas as questões requerem deliberação a todo o momento" (MAIA, 2008, p.29).

No caso do $\mathrm{PNDH}-3$, é preciso reconhecer que os atores que buscamos identificar operam em um contexto de jogo político e, de tal modo, há uma diversidade de fatores, que vão desde o debate argumentativo a essa rede de estratégias políticas, que compõe o quadro que levou o governo a recuar e modificar o texto do PNDH-3.

Assim, não assumimos aqui a visão inocente de que a democracia deliberativa almeja conquistar um processo puramente racional e democrático. Há sempre uma diversidade de atores e de interesses e, ainda, de formas de interação política.

\footnotetext{
${ }^{3}$ No original: "justifications require that citizens go beyond the self-interests typical in preference aggregation and orient themselves to the common good".
} 
Tais discussões são interessantes para a reflexão sobre o modo como se dá a tomada de decisão política. O próprio Habermas $(1997,1989)$ reconhece que o uso do argumento para resolver impasses é algo irregular no mundo prático das interações cotidianas. $O$ autor afirma que "os meios de se chegar ao acordo são constantemente colocados de lado pelos instrumentos da força. Assim, a ação que é orientada aos princípios éticos tem que se acomodar aos princípios que derivam não de princípios, mas de necessidade estratégica" (HABERMAS apud MAIA, 2008, p.34).

\section{Método: a adaptação do $D Q I$}

Para problematizarmos a questão da justificação, o trabalho analítico foi dividido em duas etapas. Em um primeiro momento, analisamos as justificativas dadas para a mudança e para a manutenção do PNDH-3 encontradas na cobertura midiática. Nesse momento, buscamos caracterizar a visibilidade que os media concederam ao caso, identificando os atores e os posicionamentos preponderantes, bem como as características das justificações (o nível de justificação, de respeito e o tipo de conteúdo fundamentado no bem comum ${ }^{4}$ ou no interesse de grupo presentes nos argumentos). O material analisado foi retirado dos jornais Folha de São Paulo, o Globo, Estado de Minas, e dos telejornais Jornal Nacional, Jornal da Band e Jornal da Record e corresponde ao período de janeiro a maio de 2010, quando o debate nos media foi maior.

Nessa primeira etapa analítica, o material foi analisado por meio do método DQI (Discourse Quality Index). O DQI é um método

\footnotetext{
${ }^{4}$ Reconhecemos que o termo bem comum pode apresentar diferentes acepções. Na perspectiva utilitarista, o "bem comum" pode ser entendido como a melhor solução para o maior número possível de pessoas. Para o pluralismo, o termo pode ser entendido como a melhor decisão para a sociedade, pensada de forma abstrata, genérica. Para proceder a codificação, compartilhamos de ambas perspectivas para identificar posicionamentos que utilizam o ideal de bem comum em sua argumentação, conforme é proposto pela própria metodologia DQI de Steiner et al. (2004), a qual embasa esse estudo.
} 
quantitativo, de análise da deliberatividade de debates parlamentares, desenvolvido por Steiner e seus colegas desde 1998 (STEINER et al., 2004, 2012). O método parte da leitura dos textos do debate, com a identificação das partes relevantes, as quais são, então, submetidas a uma codificação. Neste trabalho iremos adaptar o método DQI para os propósitos de nossa pesquisa e, por isso, utilizamos as variáveis que medem o nível de sofisticação das justificações dadas pelos participantes, o nível de respeito pelo adversário presente nos argumentos e o conteúdo que define a justificativa (se é fundamentado tendo em vista o bem comum ou o interesse de um grupo específico) ${ }^{5}$.

Em uma segunda etapa analítica, buscamos comparar os discursos que permearam as questões presentes em dois conflitos específicos do PNDH-3 (a polêmica com o agronegócio, identificada como tema 1 em nossa análise, e com as Forças Armadas, identificada como tema $2)^{6}$. Esse momento buscou observar as nuances que diferenciam os discursos e as decisões tomadas em relação aos pontos polêmicos durante os diferentes momentos ${ }^{7}$ (criação na conferência pública, no debate mediado, na publicação final do programa) que compõem o complexo processo do PNDH-3.

\footnotetext{
${ }^{5}$ Originalmente, o DQI foi planejado para ser aplicado nos debates parlamentares. Como não tratamos de um debate face-a-face, mas de uma troca pública de razões mediada pelos meios de comunicação, algumas categorias não atenderiam às nossas condições, e, por isso resolvemos adaptar o método.

${ }^{6}$ o PNDH-3 foi alvo de maior controvérsia com os setores: religiosos (devido à discussão sobre o aborto e à proposta de retirar símbolos santos de prédios públicos), com a imprensa (porque propôs a criação de controle editorial em empresas que violassem os direitos humanos), com o agronegócio (porque propôs o estabelecimento da mediação em casos de invasão de terra, ao invés da imediata retirada dos invasores), com as Forças Armadas (porque propôs a criação de ações de memória e justiça, entre elas, a criação da Comissão da Verdade). Para este artigo, buscamos comparar o debate em torno do conflito com o agronegócio, o qual identificamos como TEMA 1, e com as Forças Armadas, que identificamos como TEMA 2.

7 Ao analisarmos o objeto em diferentes momentos nos aproximamos da abordagem sistêmica da deliberação, que considera que processo discursivo acontece espraiado no tempo e no espaço. Sobre isso, ver Mansbridge (1999), Mansbridge, Parkinson et al. (2012), Hendriks (2006), Goodin (2005), Neblo (2005), Parkinson (2006).
} 
Por meio desse mapeamento analítico, buscamos apreender a dinâmica da discussão envolvendo o PNDH-3, para refletirmos acerca dos desafios que tangem as políticas de direitos humanos no Brasil.

\section{Análise}

\subsection{Características gerais da cobertura midiática sobre o PNDH-3}

Para analisar o debate do PNDH-3 nos media, foram coletadas 293 matérias, veiculadas em seis jornais diferentes, sendo três impressos (Jornal Estado de Minas, Jornal Folha de São Paulo e Jornal o Globo) e três televisivos (Jornal Nacional, Jornal da Band e Jornal da Record). Esse número de matérias nos forneceu ao total de toda cobertura midiática o número de 793 proferimentos relevantes analisados.

De um modo geral, as matérias adotaram um posicionamento crítico em relação ao programa, ou seja, apresentavam justificativas contra o PNDH-3, representando 54\% dos proferimentos analisados. Aproximadamente $31 \%$ dos proferimentos defendiam o programa e $15 \%$ eram neutros ou balanceados, apontando os pontos "prós e contra" do documento.

A análise também mostra uma desigualdade na participação dos atores envolvidos no debate na cobertura midiática. No tema 1 , que trata do conflito do agronegócio, por exemplo, 43\% das falas são dos produtores rurais, os quais demandavam a alteração do programa. Já no caso do tema 2, que aborda o conflito dos militares com o programa, a distribuição entre os atores interessados na permanência e na alteração do programa foi equilibrada (11\% e 10\% respectivamente). Entretanto, a cobertura privilegiou os atores do Poder Executivo, que responderam por $26 \%$ dos proferimentos analisados. O gráfico abaixo ilustra os tipos de atores com cobertura mais expressiva no caso da polêmica com o agronegócio e com os militares envolvendo o programa nacional de direitos humanos. 
Gráfico 1. Tipo de ator na cobertura temática do PNDH-3

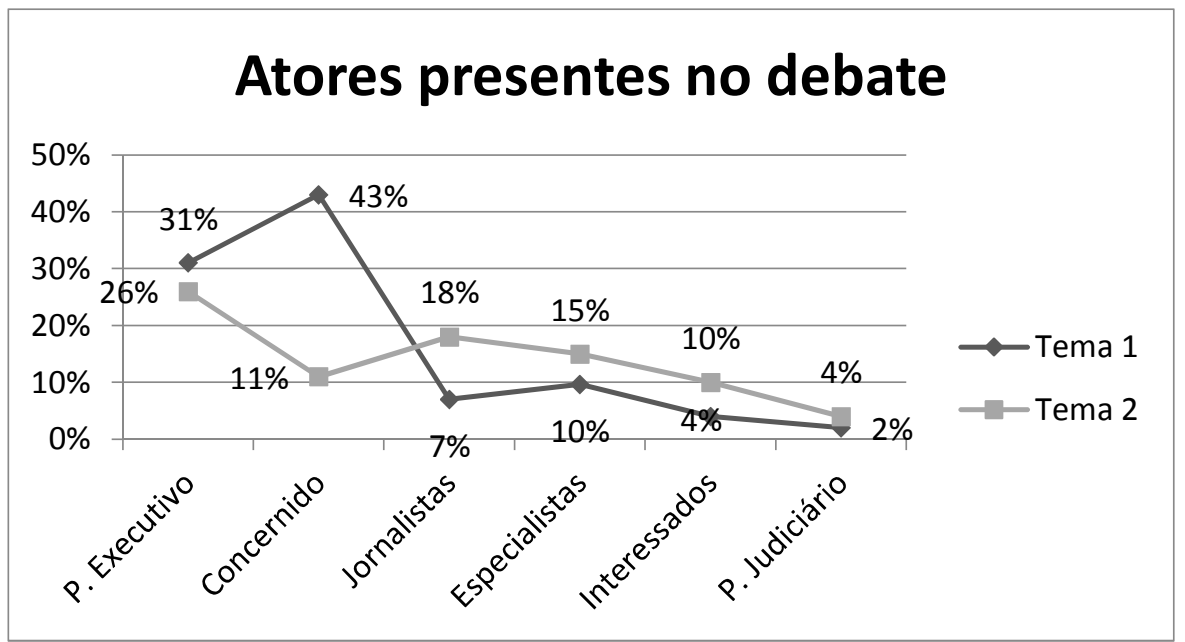

Dados: Cobertura geral (base de cálculo): 275 proferimentos

No caso do tema 1 , chama nossa atenção a visibilidade conferida à senadora Kátia Abreu (PSD-TO). A participação dela é tão expressiva que durante nossa análise a identificamos como um ator específico. Inicialmente, a senadora era classificada como sendo uma representante do ator "Poder Legislativo" e também do ator “Organizações Empresariais", uma vez que ela também é a presidente da CNA (Confederação Nacional da Agricultura). Essa visibilidade somada corresponde a $43 \%$ do tipo de ator que aparece na cobertura envolvendo a controvérsia nesse tema. $O$ outro lado da contenda (defensores do programa), que deseja a permanência do texto original do PNDH-3, refere-se a atores da sociedade civil organizada, como ONG's e movimentos sociais (o MST, por exemplo) e a cidadãos comuns (proferimentos de pequenos produtores rurais, beneficiados pela proposta do PNDH-3, poderiam ilustrar esse ator). Os dados mostram uma baixa visibilidade desses atores: apenas $4 \%$ do volume dos proferimentos. Essas informações nos mostram que a cobertura midiática concedeu mais visibilidade a atores críticos ao PNDH-3 nessa controvérsia, negligenciando atores que poderiam ser 
beneficiados com as medidas do programa. Esses atores expressivos possuem também maior capital político (são ministros de governo ou senadores) e financeiro (representam organizações empresariais importantes para a economia brasileira).

Já o tema 2, que aborda o conflito com as Forças Armadas, caracteriza-se por ter uma desigualdade na cobertura entre atores da sociedade civil e da esfera política formal. Os atores do Poder Executivo reúnem $26 \%$ dos proferimentos da cobertura. Entretanto, diferentemente do outro tema analisado, na controvérsia com os militares o ator classificado como Poder Executivo que recebeu maior visibilidade foi o ministro dos Direitos Humanos, Paulo Vanucchi, com $56 \%$ do volume dos proferimentos. Ou seja, enquanto no primeiro tema teve destaque na cobertura a fala do ministro responsável por criticar o $\mathrm{PNDH}-3$, no segundo tema analisado, o ministro responsável por justificar as críticas e defender o programa é o que recebe maior atenção. Acreditamos que isso esteja relacionado ao fato de que foi exigida uma maior responsividade do ministro Paulo Vanucchi, uma vez que a condução das críticas ao PNDH-3 dentro do tema 2 quase desencadeou uma crise de governo. O ministro da Defesa, Nelson Jobim, maior crítico do programa em relação às propostas envolvendo investigações acerca da ditadura, representa outro ator do Poder Executivo com expressiva cobertura: $20 \%$ dos proferimentos. Na cobertura desse tema, várias vezes foi noticiado que reuniões extraordinárias foram realizadas entre o ministro Nelson Jobim, os comandantes das Forças Armadas, o ministro Paulo Vanucchi e o presidente Lula. Essas reportagens destacavam que o ministro Nelson Jobim havia entregado uma carta de demissão, caso o PNDH-3 permanecesse com sua redação original. Essa é uma informação importante, que está relacionada aos desafios da prática deliberativa frente às negociações e ao jogo político, naturalizados nessa esfera. 
Por fim, destacamos a cobertura concedida a oficiais de carreira das Forças Armadas (classificados como "críticos do programa”, no gráfico 1). Os militares consideraram que o PNDH-3 feria o acordo da Lei da Anistia de 1979 e por isso se posicionaram contrários à publicação do decreto. Juntamente com o ministro Nelson Jobim, os comandantes do alto escalão ameaçaram se demitir e criticaram o governo, acusando-o de ser revanchista e tendencioso. A análise nos mostra, entretanto, que esse ator foi apenas o $4^{\circ}$ em relevância, considerando a distribuição do volume dos proferimentos nesse tema de controvérsia. $\mathrm{Na}$ cobertura geral, os militares representam $11 \%$ dos proferimentos. Acreditamos que esse é um baixo valor de visibilidade para um grupo que está diretamente interessado na condução da controvérsia. O grupo oposto aos militares - que consideramos como "defensores do programa", refere-se aos cidadãos comuns (no caso, a maioria deles tratava-se de familiares de mortos e desaparecidos políticos que não pertenciam a nenhum movimento social) e representantes da sociedade civil organizada (ONG's como a Justiça Global, e movimentos como "Tortura Nunca Mais"). Esse grupo de atores formado principalmente pela sociedade civil representa, em média, $10 \%$ da cobertura midiática. Ainda que esse não seja um dado elevado, ele se mostra bem mais expressivo do que na cobertura da polêmica envolvendo o tema 1.

Ainda sobre o acesso dos atores na cobertura midiática, a diferença percentual entre a cobertura dos críticos no Tema 1 (organizações empresariais e a senadora Kátia Abreu) e os críticos no Tema 2 (Forças Armadas) é expressiva. Enquanto no primeiro eles são responsáveis por conduzir a problematização do PNDH-3, no segundo esse processo é conduzido pelo poder Executivo, pelos especialistas e pelos jornalistas. No Tema 2, os jornalistas tiveram um papel importante no debate, com um volume alto de proferimentos (18\%) que corresponde a mais que o dobro do Tema 1 (7\%). Esse dado parece nos revelar que há um maior engajamento dos jornalistas na discussão sobre a questão da memória e justiça no Brasil, do que no 
conflito com o agronegócio, que parece interessar a um grupo mais específico da sociedade brasileira e cuja discussão é conduzida por aqueles que se relacionam diretamente com o tema.

\subsection{Análise: características do debate mediado sobre o PNDH-3}

Seguindo a proposta do DQI, buscamos avaliar em nosso corpus o nível de justificação. Assim, realizamos uma classificação dos proferimentos, apontando se eles continham apenas um posicionamento sem justificação, ou se havia um argumento que poderia ser codificado como inferior (há uma justificativa, mas a relação não é completa, não é clara), qualificado (há pelo menos uma justificação completa) ou sofisticado (há duas ou mais justificações completas).

Em geral, nos dois temas, os proferimentos apresentavam justificativas qualificadas ou sofisticadas. 0 trecho abaixo exemplifica uma justificativa que consideramos como sofisticada.

"Os militantes contra a ditadura já foram punidos, inclusive à luz da legislação do regime ditatorial existente na época no Brasil. O que é preciso fazer, até porque nunca foi feito antes, é apurar as responsabilidades daqueles que, de dentro do Estado, torturaram e mataram", afirma Marcelo Zelic, vicepresidente do Grupo Tortura Nunca Mais de São Paulo (FOLHA DE SÃO PAULO, Entidades de direitos humanos rechaçam mudanças no plano, 11 de janeiro de 2010).

O exemplo pode ser classificado como uma justificativa sofisticada porque apresenta duas razões completas para amparar o posicionamento que apoia a criação de uma Comissão da Verdade. A primeira é o fato de haver uma desigualdade, visto que os militantes já foram punidos pela ditadura. O segundo argumento é de que o país precisa apurar as responsabilidades, algo que ainda não foi feito. 
O gráfico abaixo nos mostra os dados do nível de justificação nos temas em que estamos analisando comparativamente, os Temas $1 e$.

Gráfico 2. Nível de justificação

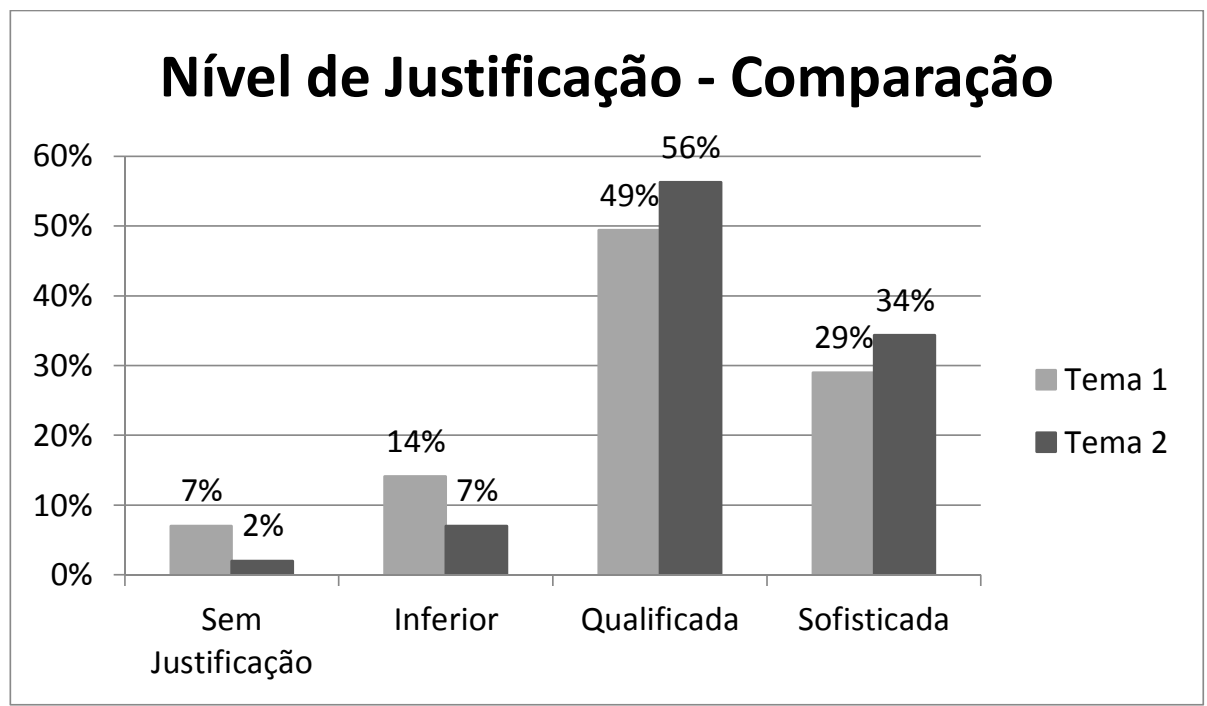

Dados: Cobertura geral (base de cálculo): 275 proferimentos

A investigação nos mostrou que a troca de razões em torno do programa de direitos humanos caracterizou-se por apresentar, em sua maior parte, proferimentos qualificados ou sofisticados. Essa é uma informação interessante, pois a existência de um processo que preza pela argumentação contribui para a constatação de que a mídia pode ser uma arena deliberativa, e enfraquece a perspectiva de que não há espaço para discussões e produções com qualidade nos meios de comunicação de massa.

A segunda variável do DQI utilizada na análise empírica era relacionada ao interesse do conteúdo presente nos argumentos oferecidos no debate. Nessa categoria do DQI, procuramos identificar se o conteúdo era justificado como sendo do interesse de um grupo específico ou se o interesse era relativo ao bem comum. 
A maior parte dos proferimentos, nos dois temas, era fundamentada em interesses particulares, que diziam respeito a apenas um grupo da sociedade. Entretanto, esse quadro é bem mais acentuado no Tema 1, como podemos verificar no gráfico.

Gráfico 3. Comparação sobre o interesse do conteúdo exposto nas justificativas dos proferimentos

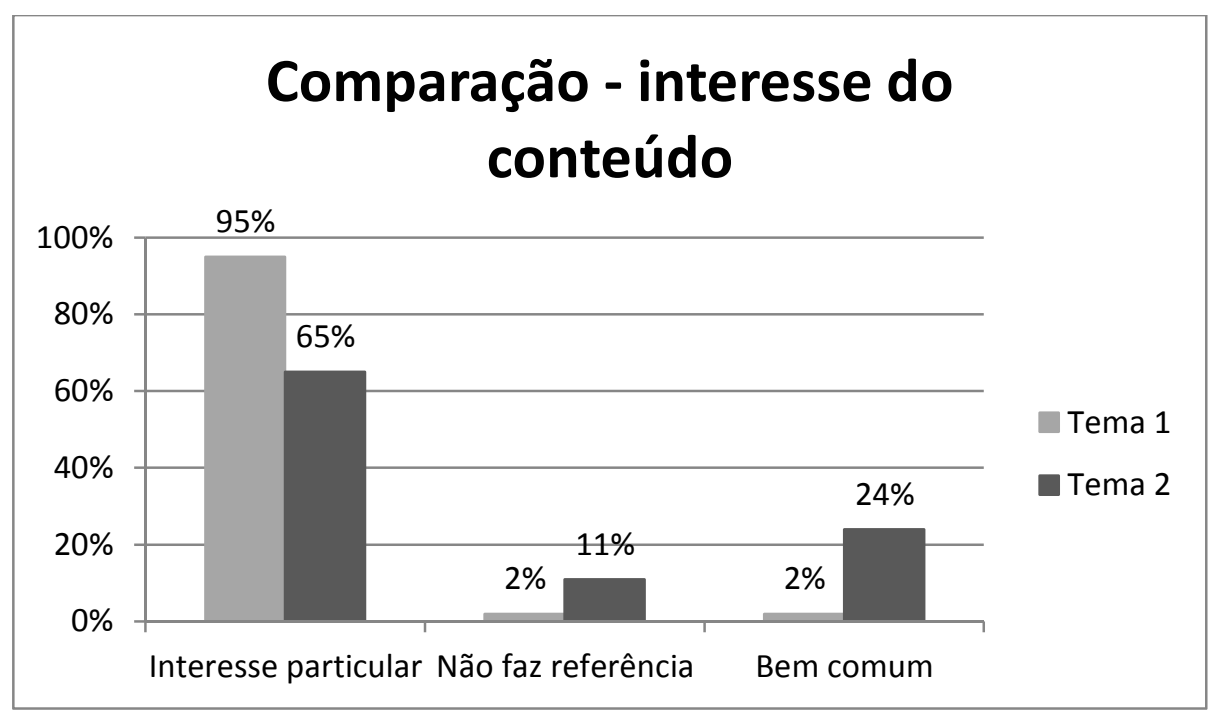

Dados: Cobertura geral (base de cálculo): 275 proferimentos

Uma fala do jurista Ives Gandra Martins ilustra como o proferimento pode abordar apenas o interesse de um determinado grupo da sociedade brasileira. No dia 11 de janeiro de 2010, o telejornal Jornal da Band exibiu a matéria "Decreto sobre direitos humanos do governo Lula recebe críticas de todos os lados", contendo uma entrevista com o jurista. Segundo ele, "O que eles [o governo, com o PNDH-3] estão pretendendo é dar direito àquele que invadir qualquer terra, fazer com que, uma vez invadida, o direito de propriedade deixa de ser do proprietário e passe a ser do invasor". 0 proferimento ressalta o interesse particular dos proprietários de terra, e ignora, por exemplo, a demanda pela reforma agrária, necessária à nação. 
A deliberação pode ser entendida como um processo inclusivo, em que participantes com iguais condições apresentam suas razões, e procuram considerar as perspectivas dos outros a fim de tornar o resultado mais justo. Nesse processo, é natural que a argumentação preze pelos interesses individuais ou de grupos, uma vez que os participantes pretendem mostrar a importância de suas posições. Todavia, espera-se também que ao longo do debate essas razões se transformem, de modo que seja considerado o bem coletivo, ou seja, é necessário que os participantes da deliberação estejam abertos às demandas e perspectivas dos outros. No caso do PNDH-3, percebemos que as justificativas trazem e reforçam o interesse de grupos ao longo de todo o debate. Por se tratar de uma política de direitos humanos e pelo fato de se esperar dos participantes uma postura aberta a conhecer as demandas e justificativas dos outros atores, a expectativa era de que ao longo da controvérsia a argumentação se tornasse mais pautada no bem coletivo, o que não aconteceu.

Em relação ao nível de respeito nos proferimentos analisados, identificamos que o tratamento neutro em relação aos outros grupos da contenda foi maioria, o que era esperado. Entretanto, há também um elevado índice de falas que abordam de modo desrespeitoso outros grupos. $\mathrm{Na}$ polêmica envolvendo os militares, os proferimentos desrespeitosos representam $38 \%$ das falas, e no conflito com o agronegócio, esse número alcança quase metade dos proferimentos (47\%), sendo que nesse último caso a diferença percentual entre os proferimentos neutros e desrespeitosos foi de apenas $3 \%$. 
Gráfico 4. Comparação sobre o nível de respeito presente nas justificativas em relação aos outros argumentos ou outros atores

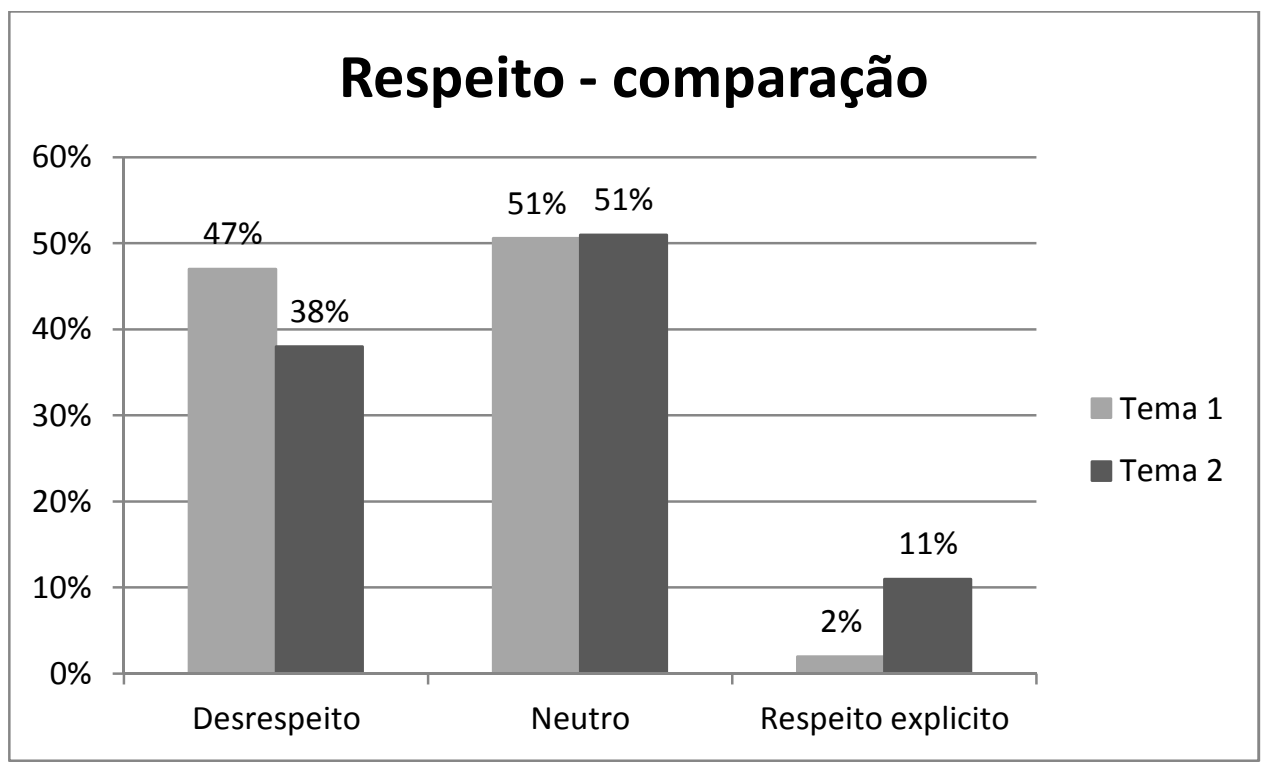

Dados: Cobertura geral (base de cálculo): 275 proferimentos

Essa constatação apresentada no gráfico acima revela que o ideal deliberativo que demanda que os participantes considerem uns aos outros como iguais não é alcançado. Partindo dos princípios da democracia deliberativa, esperamos que a troca de razões preze por um processo de civilidade, em que os participantes se reconhecem como iguais e, portanto, respeitam-se. Essa característica também é ressaltada por Wessler e Schultz (2007), quando os autores analisam o potencial de deliberação nos media. Os autores afirmam que o processo de argumentação na mídia massiva fundamenta-se em três pilares normativos: a) igual oportunidade de acesso de ideias e argumentos; b) um ambiente de mútuo respeito e civilidade para a troca de razões e c) desacordos solucionados em curto e médio prazo por meio da razão e da inovação. Além disso, é preciso lembrar que, diferentemente da interação face a face, em que há a possibilidade de um acaloramento do debate, é comum que a interação mediada pelos meios de comunicação seja filtrada. Os jornais podem editar falas, obedecendo aos padrões de objetividade e neutralidade da 
linguagem jornalística e preservando a audiência, e, ainda assim, apresentar a polêmica que está sendo discutida.

O tratamento desrespeitoso não é esperado na linguagem jornalística, nem nos procedimentos da deliberação. Esse tipo de tratamento também não é esperado no tema da discussão (direitos humanos), uma vez que, mesmo ele abrangendo um largo espectro de interesses conflituosos, ele seja também a maior representação da tentativa em promover a paz e a igualdade social. A análise comparada dos temas nos mostra que predomina a justificativa neutra, mas ressalta-se que o tema envolvendo o conflito com o agronegócio possui falas mais agressivas, desrespeitando com mais frequência sujeitos com interesses opostos. Como exemplo, citamos a utilização recorrente de termos como "tomadores de terra", "passar o rolo compressor", "paranoia ideológica".

\subsection{Análise comparativa sistêmica dos dois temas}

Após a análise da cobertura midiática de dois temas controversos do PNDH-3, realizamos uma breve análise que considera a dinâmica de diferentes momentos deliberativos do PNDH-3. Ao correlacionarmos essas duas análises, podemos apontar algumas conclusões acerca da condução da política de direitos humanos no Brasil.

Começamos apontando os resultados da análise da controvérsia envolvendo o conflito com o setor do agronegócio. Este ator reivindicou alterações do programa relacionado à proposta de instituir a mediação dos conflitos como critério inicial para a solução de conflitos quando há a invasão de terra. Os grandes produtores rurais sustentavam que essa medida causaria uma insegurança jurídica no campo, atrasaria processos de reintegração de posse, violaria o direito à propriedade privada, prejudicaria a produção agrícola brasileira e estimularia a ação de grupos que invadem 
terras. Essa questão teve a redação alterada no novo PNDH-3, mas não foi revogada.

Ao compararmos essa questão ao longo do tempo, observamos que a proposta elaborada durante o momento de criação do PNDH-3, nas conferências públicas entre sociedade civil e Estado, foi incorporada à primeira versão do programa. Durante o segundo momento, de debate midiático, percebemos que essa proposta é refutada pelo setor do agronegócio, sendo objeto de ampla discussão. Os dados demonstrados na seção anterior demonstram que o debate é agonístico: o posicionamento dos proferimentos foi expressivamente contrário ao programa de direitos humanos (80\%) e as justificativas foram majoritariamente fundamentadas no interesse particular, chegando ao nível de 95\%, a despeito do bem comum. Como já afirmamos, ainda que os proferimentos tenham sido, na maior parte, neutros no tratamento em relação a outros grupos (51\%), a tematização dessa controvérsia apresentou um índice alto de proferimentos explicitamente desrespeitosos (47\%). É preciso lembrar que os atores mais acionados nesse debate foram as organizações empresariais e a senadora e presidente da CNA, Kátia Abreu, com $43 \%$ das falas analisadas. Esses dados nos mostram como a abordagem do conflito com os interesses do agronegócio caracterizou-se por ser mais agressiva, especialmente se comparada ao outro tema. Entretanto, essa estratégia de justificação não parece ter sido a mais exitosa. No terceiro momento, quando houve a publicação da nova versão do $\mathrm{PNDH}-3$, os produtores rurais permaneceram insatisfeitos com o programa. A nova redação dessa proposta retirou a inserção da mediação de conflitos em caso de invasão, mas manteve a proposta de realizar audiências públicas para discutir os conflitos agrários, acrescentando a presença do Incra. Apesar de a mudança ir além de uma simples alteração redacional, o setor do agronegócio não ficou satisfeito, pois demandava a total revogação dessa proposta. 
Por outro lado, a dinâmica discursiva envolvendo o conflito com as Forças Armadas apresenta características opostas. Diferentemente do agronegócio, os militares aceitaram as transformações do PNDH3 , tanto que ao ser publicada a nova versão do decreto já não foi identificada na cobertura nenhuma crítica desses atores em relação ao programa.

A publicação da nova versão do PNDH-3 traz quatro importantes alterações em relação ao eixo de memória e verdade do programa de direitos humanos. Nenhum item foi revogado, mas foram feitas alterações redacionais importantes. A proposta de acompanhar e monitorar a tramitação judicial de processos que envolvem crimes cometidos pelo regime militar passou por uma nova redação, cujo efeito prático se mantém - que é a investigação dos crimes - mas que perde em seu valor simbólico. O decreto 7177/10, que traz a nova versão do PNDH-3, diz que serão investigadas as "graves violações de direitos humanos praticadas no período fixado no art. $8^{\circ}$ do Ato das Disposições Constitucionais Transitórias da Constituição de 1988". Há, então, duas mudanças:

- ao invés da afirmação direta de que serão investigados os “atos relativos ao regime de 1964-1985" - como estava na primeira versão do PNDH-3 e como era proposto no primeiro momento (BRASIL, 2009a,b), na criação do programa durante as conferências públicas - a nova redação apresenta um objeto de investigação mais genérico, que não relaciona diretamente a ditadura militar. Tratam-se das "graves violações de direitos humanos".

- A segunda mudança é em relação ao período de investigação. Enquanto a ideia inicial era investigar o período da ditadura, ou seja, 1964-1985, o decreto final estabelece o tempo previsto na Constituição, que é de 1946-1988, enfraquecendo a importância de se investigar especificamente a ditadura militar brasileira. 
Esse ponto alterado foi o único objeto de discussão na mídia, entretanto, não foi a única proposta a ser alterada envolvendo a questão. Também foram alteradas as propostas de:

1) alteração da questão da sinalização de locais públicos que serviram para tortura durante a ditadura;

2) produção de materiais didáticos e pedagógicos que informam sobre a repressão durante o regime militar;

3) alteração e proibição de que logradouros e prédios públicos tenham nomes de pessoas que violaram os direitos humanos durante o regime militar.

Essas questões não foram tematizadas na cobertura midiática e, por isso, acreditamos que a alteração deles foi resultado de pressão exercida nos bastidores da política. Essas modificações são significativas $^{8}$. O primeiro perdeu a ênfase inicial de criar mecanismos sistemáticos para a promoção da memória, o segundo item realiza uma troca de termos, que o torna mais genérico e esvazia a força simbólica, tais como: a substituição da proposta de investigar a "repressão política" para investigar "violações de direitos humanos", e a substituição do período a ser investigado: deixa de ser de 1961 a 1984 para tratar o período indicado no artigo 8º da CF de 1988 (o período de 1946 a 1988). Já o terceiro ponto deixa de propor uma legislação que trate da substituição de logradouros públicos com nomes de repressores para apenas propor o fomento do debate sobre a questão.

Lembramos que a tematização do conflito do PNDH-3 com as Forças Armadas nos media caracterizou-se por ser mais equilibrada. A maior parte dos proferimentos era a favor do programa de direitos humanos (56\%) e as justificativas eram, em sua maioria, qualificadas

\footnotetext{
${ }^{8} \mathrm{O}$ detalhamento dessas transformações pode ser encontrado na dissertação "Direitos Humanos e suas justificativas na mídia: a controvérsia envolvendo o caso do PNDH-3", de minha autoria.
} 
ou sofisticadas ( $90 \%$, se somadas as duas categorias). Apesar dos proferimentos serem majoritariamente fundamentados em interesses particulares (65\%), há um elevado índice de argumentos relacionados ao bem comum (24\%), principalmente se esse índice é comparado com o outro tema em análise. 0 nível de respeito neutro em relação a outros grupos também é superior (51\%), com $11 \%$ de proferimentos elogiosos a outros grupos. O nível de desrespeito a outros grupos não é baixo (38\%), mas é menor do que no outro tema.

Ainda assim, ao correlacionarmos os diferentes momentos envolvendo a controvérsia com a questão da ditadura militar, observamos que a cobertura midiática foi mais equilibrada, contudo, levou a mudanças significativas, pois afetam principalmente o valor simbólico da luta pela memória e verdade no Brasil.

A tabela a seguir sintetiza os resultados comparativos dos dois temas envolvendo o PNDH3:

Tabela 1. comparação dos principais achados nos dois temas analisados

\begin{tabular}{|c|c|c|}
\hline & TEMA 1 & TEMA 2 \\
\hline Satisfação com as mudanças & Não & Sim \\
\hline $\begin{array}{l}\text { Posicionamento da cobertura } \\
\text { midiática }\end{array}$ & $80 \%$ contra & $56 \%$ favor \\
\hline Ator com maior expressividade & $43 \%$ "críticos" & $\begin{array}{l}26 \% \text { poder } \\
\text { executivo }\end{array}$ \\
\hline Nível de Justificação & $\begin{array}{l}78 \% \text { sofisticada } \\
\text { ou qualificada }\end{array}$ & $\begin{array}{l}90 \% \text { sofisticada } \\
\text { ou qualificada }\end{array}$ \\
\hline Interesse da Justificação & $\begin{array}{l}2 \% \text { bem comum } \\
95 \% \text { interesse } \\
\text { particular }\end{array}$ & $\begin{array}{l}24 \% \text { bem } \\
\text { comum } \\
65 \% \text { interesse } \\
\text { particular }\end{array}$ \\
\hline Nível de respeito & $\begin{array}{l}51 \% \text { neutro } \\
47 \% \text { desrespeito } \\
2 \% \text { respeito }\end{array}$ & $\begin{array}{l}51 \% \text { neutro } \\
38 \% \\
\text { desrespeito } \\
11 \% \text { respeito }\end{array}$ \\
\hline
\end{tabular}


4. Apontamentos: o que a exposição do PNDH-3 nos media nos diz sobre os direitos humanos no Brasil?

Os dados da análise da troca argumentativa que acontece no espaço midiático nos mostram a potencialidade dos meios de comunicação de serem compreendidos como arenas deliberativas. Há espaço para argumentação nos media, e a visibilidade que eles (os media) concedem é um importante fator na tomada de decisão política. Entretanto, elementos como a distribuição da participação dos atores e o modo de enquadramento da discussão são questões que ainda chamam a atenção por não seguirem os critérios de inclusividade e de liberdade do debate. Por isso, a realização de trabalhos que investiguem a deliberação empiricamente e o desenvolvimento de metodologias que consigam apreender essas características, como pretende o DQI, mostram-se tão interessantes.

Ao realizarmos uma análise sobre a correlação entre o debate midiático e as decisões políticas tomadas em relação ao PNDH-3, percebemos que as mudanças publicadas na nova versão do documento são essencialmente redacionais. Isso não implica dizer que elas fora menores, pelo contrário. A mudança no programa de direitos humanos produz duas consequências:

1) desconsidera as resoluções produzidas no âmbito da Conferência Nacional de Direitos Humanos. Ainda que as conferências públicas apresentem problemas sobre o modo como são realizadas ${ }^{9}$, especialmente sobre o acesso à participação e à prática de reforçar discursos militantes que já chegam prontos ao espaço de deliberação, é preciso ressaltar que a $11^{\mathrm{a}} \mathrm{CNDH}$ foi convocada e definida pelo o próprio governo como o lugar onde o PNDH-3 deveria ser elaborado. Logo, a mudança no $\mathrm{PNDH}-3$ representa um ato que enfraquece o próprio governo, à medida que ele retira a legitimidade de um espaço que ele mesmo idealizou.

2) a mudança redacional altera em diferentes níveis as ações práticas do programa, mas afeta, especialmente, o significado simbólico. É preciso ressaltar que as reivindicações de grupos da sociedade civil que lutam pela promoção dos direitos humanos referem-se a

\footnotetext{
${ }^{9}$ Sobre isso, ver: AVRITZER, 2010: FARIA et al., 2012: PIRES et al., 2012.
} 
mudanças práticas (como edições de leis), mas tratam também da transformação moral da sociedade.

Outra questão a ser ressaltada é em relação à estratégia do governo em contornar a polêmica em torno do programa. Nos dois temas analisados (conflito com o agronegócio e com os militares) não houve nenhuma revogação, mas alterações redacionais. Essa constatação pode revelar que o governo, para sair da polêmica em torno do PNDH-3, a qual ameaçava uma crise de governo em pleno ano eleitoral, agiu conciliando dois interesses:

1) ao não revogar os pontos controversos, ele não rompe por completo com a sociedade civil que havia participado do debate durante as conferências públicas;

2) O governo, ao mudar a redação, tenta atender os interesses dos grupos que criticavam o PNDH-3, pois há um apaziguamento da linguagem utilizada.

Essa constatação reforça a importância da justificativa nos processos políticos. Ainda que a ação do governo possa ser interpretada como um agir estratégico, que tenta conciliar diferentes interesses, podemos perceber também que a solução adotada é discursiva. Ou seja, não temos elementos suficientes para afirmar se o resultado final da controvérsia envolvendo o PNDH-3 e que encerra o conflito foi ou não produto de barganhas ou negociações de cargos políticos. O que podemos apreender é que, em uma democracia, os governantes são compelidos a justificar suas ações. E essa constante reivindicação de accountability, mesmo em casos que não podemos afirmar a sinceridade, das intenções e das negociações dos participantes nos bastidores, pode levar a uma dinâmica deliberativa. No caso do PNDH-3, percebemos que o resultado final foi a publicação de uma nova versão do programa. A nova publicação representa uma nova argumentação do governo frente à sua política de direitos humanos.

Por fim, destacamos que o resultado de nossa análise revela um conflito entre uma solução discursiva que afeta principalmente o 
valor simbólico das lutas no campo dos direitos humanos no país. Tal constatação remete-nos à discussão sobre o Brasil real versus o Brasil Legal, presente na literatura sobre direitos humanos no nosso país. Fazemos tal relação, pois, analisando-se a proposta do PNDH-3, podemos observá-la como uma arrojada política pública, uma vez que representa as demandas da sociedade civil apresentadas durante a $11^{\text {a }}$ Conferência Nacional de Direitos Humanos e aborda mais de 40 questões, cujas ações são mais detalhadas se comparadas às propostas do PNDH-1 e PNDH-2. A versão do programa de direitos humanos que analisamos também representa uma importante resposta do país a organismos internacionais.

Contudo, quando analisamos o objeto em relação às controvérsias que ele suscitou, o cenário é menos positivo. Observamos um acirrado debate em torno de quatro questões específicas dentro da amplitude do programa: conflitos com setores do Agronegócio, com a Igreja, com a Imprensa e com os Militares, todos envolvendo atores tradicionais da elite brasileira. As justificativas dadas foram, em sua maioria, qualificadas ou sofisticadas em relação à constituição da argumentação, mas também possuíam índices elevados de desrespeito a outros grupos e de defesa de interesses privados ao invés do bem comum. Ao final, o governo retrocedeu, alterando diversos pontos do programa. O novo PNDH-3 não perdeu sua essência, mas trocou e incluiu palavras que esvaziaram a luta pela promoção dos direitos humanos realizadas por grupos da sociedade civil.

Diante dessa constatação, a citação abaixo de Paulo Sérgio Pinheiro contribui para refletirmos sobre esse processo.

Mesmo que a consolidação democrática se aprofunde, com a reforma das instituições e da legislação, as garantias plenas do estado de direitos humanos somente podem vir a ser reais se o movimento dos direitos humanos souber estar ligado às aspirações populares. Não basta a formalidade democrática: em 


\begin{abstract}
muitos países desenvolvidos os sistemas governamentais de proteção dos direitos humanos, que apenas começamos a conquistar, já começam a apresentar sinais de inadequação diante dos desafios contemporâneos (novas formas de racismo, migrações, narcotráfico, crime organizado). Jamais se deve perder de vista a necessidade de articular as lutas pelas reformas institucionais, pelos sistemas nacionais e internacionais de proteção, com o atendimento emergencial das reivindicações das populações cujo acesso à cidadania tem sido tradicionalmente barrado. (PINHEIRO, 2006, p.45).
\end{abstract}

Como Pinheiro afirma, a efetivação dos direitos humanos no Brasil depende de que as decisões políticas estejam diretamente associadas às demandas da sociedade. $\mathrm{O}$ PNDH-3 ao ser construído por meio das conferências públicas parece ir por um caminho que tenta resolver o hiato que há entre as garantias do Estado e as aspirações da população (PINHEIRO, 2006). Ainda assim, existe um conflito entre um Brasil real e um Brasil legal (MONDAINI, 2009). Esse pensamento deve-se à existência de um descompasso entre as garantias normativas do país, que possui leis avançadas para a consolidação dos direitos universais, e a realidade da população, submetidas a diversas formas de violação de sua dignidade humana, com desigualdades arraigadas.

A estrutura sobre a qual o PNDH-3 foi construído mostrou-se ser ainda insuficiente. Permanece a existência de desafios para o amadurecimento da democracia e para a efetividade dos direitos universais no Brasil. Nesse sentido, a análise das justificativas - as falas, os argumentos, as razões imersas na sociedade - que são dadas para sustentar posições que podem contribuir ou retroceder nas políticas de direitos humanos no Brasil nos parece interessante como constante objeto de reflexão acerca do significado desses direitos em nossa sociedade. 


\section{Referências}

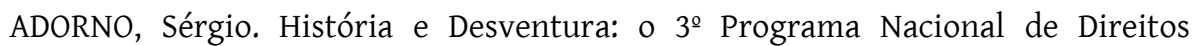
Humanos. In: Revista Novos Estudos, v.86, 2010, pp. 5-20.

AVRITZER, L. (Org.) Experiências nacionais de participação social. Belo Horizonte: Cortez Editora, 2010.

BARAZAL, Neusa R. A versão brasileira dos direitos humanos: uma reflexão política-antropológica dos PNDH I e II. In: Cadernos Prolam/USP, ano 4, v.1, 2005, pp. 35-60.

BRASIL. Secretaria de Especial de Direitos Humanos (SEDH). Relatório Final $11^{a}$ Conferência Nacional de Direitos Humanos. Brasília: 2009a.

BRASIL. Secretaria de Especial de Direitos Humanos (SEDH). Texto-base para a 11 Conferência Nacional de Direitos Humanos: Democracia, desenvolvimento e direitos humanos - superando as desigualdades. Brasília: 2009b.

BRASIL. Secretaria de Especial de Direitos Humanos (SEDH). Terceiro Programa Nacional de Direitos Humanos. Brasília: 2010.

BOHMAN, James. Public Deliberation: Pluralism, Complexity and Democracy. Cambridge, MA: MIT Press, 1996.

CHAMBERS, S. Rhetoric and the Public Sphere: has Deliberative Democracy abandoned mass democracy? In: Political Theory, v.37, n 3, 2009, pp. 323-350.

Measuring Publicity's Effects: reconciling Empirical Research and Normative Theory. In: Acta Politica, vol. 40, nำ2, 2005, p. 255-266. 2003, p. 307-26.

Deliberative Democratic Theory. In: Annual Review of Political Science, v. 6,

COHEN, J. Deliberation and democratic legitimacy. In: BOHMAN, J.; REHG, W. (Eds.). Deliberative democracy. London: MIT Press, 1997, pp. 67-92.

DALLARI, Dalmo de Abreu. "Direitos Humanos no Brasil: uma conquista difícil". In: Cinquenta Anos da Declaração Universal dos Direitos Humanos. São Paulo: Centro de Estudos Konrad Adenauer Stiftung, 1998.

DRYZEK, John, Deliberative Democracy and Beyond: Liberals, Critics, Contestation. Oxford: Oxford University Press, 2000.

FARIA, C. F. ; SILVA, V. P. E. ; LINS, I. L. Conferências de políticas públicas: um sistema integrado de participação e deliberação? In: Revista Brasileira de Ciência Política, v. 7, 2012, pp. 249-284.

GOMES, Wilson; MAIA, Rousiley, Celi Moreira. Comunicação e Democracia: problemas e perspectivas. São Paulo: Ed.Paulus, 2008. 
GOMES, Wilson. Transformações da política na era da comunicação de massa. São Paulo: Ed. Paulus, 2004.

GOODIN, R. Sequencing deliberative moments. In: Acta Politica, v.40, 2005, pp. 182196.

GREGORI, José. O Primeiro Programa Nacional de Direitos Humanos. In: SEDH (org). Brasil: a realidade do país aos 60 anos da Declaração Universal. Brasília: 2008.

GUTMANN, A., THOMPSON, D. The Scope of Accountability. In: Democracy and disagreement. Cambridge:Harvard University Press, 1996, pp. 128-164).

Press, 2004.

Why Deliberative Democracy? Princeton, NJ: Princeton University

HABERMAS, J. Direito e democracia: entre facticidade e validade. Rio de Janeiro: Tempo Brasileiro, 1997, v. I e II.

HABERMAS, J. Para o uso pragmático, ético e moral da razão prática. In: Revista Estudos Avançados, vol.3, no7, 1989, pp. 4-19.

HENDRIKS, Carolyn, M., Integrated deliberation: reconciling civil society's dual role in deliberative democracy. In: Political Studies, 54, 2006, pp. 486-508.

LIMA JÚNIOR, Jayme Benvenuto. O caráter expansivo dos direitos humanos na afirmação de sua indivisibilidade e exigibilidade. In: LYRA, Rubens P. (Org.). Direitos Humanos: os desafios do século XXI. Brasília: Editora Jurídica, 2002.

MANSBRIDGE, J. Everyday Talk in the Deliberative System. In: MACEDO, S. (Ed.) Deliberative Politics: Essays on 'Democracy and Disagreement. New York: Oxford University Press, 1999, pp.211-39.

MANSBRIDGE,J.; PARKINSON, J. et al.(Eds.). Deliberative Systems. Cambridge: Cambridge University Press, 2012.

MAIA, Rousiley Celi Moreira. Deliberation, the Media and Political Talk. New York: Hampton Press, 2012.

MAIA, Rousiley Celi Moreira. Mídia e Deliberação. Rio de Janeiro: Editora FGV, 2008.

MONDAINI, Marco. Direitos Humanos no Brasil. São Paulo: Editora Contexto, 2009.

NEBLO, M. Thinking through Democracy: Between Theory and Practice of Deliberative Politics. In: Acta Politica, n. 40, 2005, pp.169-81.

OLIVEIRA, V. V. Direitos Humanos e suas justificativas na mídia: a controvérsia envolvendo o caso do PNDH-3. Dissertação de Mestrado. Programa de Pós-Graduação em Comunicação Social da Universidade Federal de Minas Gerais. Belo Horizonte, 2013. 
PARKINSON, J. Deliberating in the Real World: Problems of Legitimacy in Deliberative Democracy. Oxford: Oxford University Press, 2006.

PINHEIRO, P.S. O passado não está morto: nem é passado ainda. In: DIMENSTEIN, G. Democracia em pedaços: direitos humanos no Brasil. São Paulo: Companhia das Letras, 2006.

PIRES, R., FONSECA, I., CRUXEN, I., ALENCAR, J., RIBEIRO, U. Participação social e desigualdades nos conselhos nacionais. Paper apresentado no $8^{\circ}$ Encontro da ABCP. Gramado, 2012.

STEINER, J.; BACHTIGER, A.; SPORNDLI, M.; STEENBERGEN, M. Deliberative Politics in Action: Analysing Parliamentary Discourse. Cambridge: Cambridge University Press, 2004.

STEINER, Jurg. The foundations of deliberative democracy: empirical research and normative implications. Cambridge, MA: Cambridge University Press, 2012.

\section{Agradecimentos}

Este artigo é parte da dissertação intitulada "Direitos Humanos e suas justificativas na mídia: a controvérsia envolvendo o caso do PNDH-3", que recebeu menção honrosa no Prêmio Compolítica de Dissertação, em 2013. Agradeço as contribuições dos professores da banca de defesa, Dr ${ }^{a}$ Regina Helena Alves da Silva e Dr. Pedro Mundim, dos colegas do Grupo de Pesquisa em Mídia e Esfera Pública (EME/UFMG), e especialmente à generosa orientação da prof. $\stackrel{a}{ }$ Dr. $\stackrel{a}{ }$ Rousiley Celi Moreira Maia.

Uma versão similar a esse texto foi apresentada no $2^{\circ}$ Simpósio Nacional sobre Democracia e Desigualdades, realizado no Instituto de Ciência Política (IPOL) da Universidade de Brasilia (UnB), em maio de 2014.

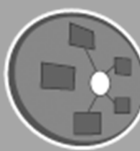

COMPOITTICA ASSOCIACCÃO BRASILEIRA DE PESQUISADORES EM COMUNICACEÅ E POLITIIICA

Presidente: Alessandra Aldé (UERJ)

Vice-Presidente: Luis Felipe Miquel (UnB)

Secretário Executivo: Francisco Jamil Marques (UFC)

Editoras-Chefes:

Alessandra Aldé (UERJ) e Maria Helena Weber (UFRGS)

Editores Executivos:

Edna Miola (UFS), Fernanda Sanglard (UERJ), Rafael

Cardoso Sampaio (UFMG) e Viktor Chagas (UFF)

Revisoras:

Fernanda Sanglard (UERJ) e Isabele Mitozo (UFPR)
A Revista Compolítica é uma revista eletrônica da Associação Brasileira de

Pesquisadores em Comunicação e Política. Com periodicidade semestral, sua proposta é difundir a produção acadêmica relacionada às interfaces desses campos de estudo.

\section{Ao citar este artigo, utilize a seguinte referência bibliográfica}

OLIVEIRA, Vanessa Veiga de. Desafios para o avanço dos direitos humanos no Brasil: uma análise das justificações no debate mediado em torno do caso do PNDH-3. In: Revista Compolítica, n. 4, vol. 2, ed. agosto-dezembro, ano 2014. Rio de Janeiro: Compolítica, 2014. 
